\title{
Le gestionnaire de projet face aux défis des bibliothèques du XXI ${ }^{\mathrm{e}}$ siècle
}

The Project Manager and the Challenges of Libraries in the $21^{\text {st }}$
Century

\section{El gestor del proyecto ante los desafíos de las bibliotecas del siglo xxi}

\section{Jean Roy}

Volume 60, numéro 2-3, avril-septembre 2014

Bibliothèques et architecture

URI : https://id.erudit.org/iderudit/1025526ar

DOI : https://doi.org/10.7202/1025526ar

Aller au sommaire du numéro

Éditeur(s)

Association pour l'avancement des sciences et des techniques de la documentation (ASTED)

\section{ISSN}

0315-2340 (imprimé)

2291-8949 (numérique)

Découvrir la revue

Citer cet article

Roy, J. (2014). Le gestionnaire de projet face aux défis des bibliothèques du XXI siècle. Documentation et bibliothèques, 60(2-3), 136-137.

https://doi.org/10.7202/1025526ar
Résumé de l'article

Le gestionnaire de projet doit s'adapter à de nombreuses contraintes, dont de nouvelles d'ordre technologique et environnemental. Quatre exemples servent à illustrer cette évolution de son rôle : la Grande Bibliothèque, les Bibliothèques du Boisé et Saul-Bellow de la Ville de Montréal, et la future bibliothèque du site Outremont de l’Université de Montréal.
Tous droits réservés (C) Association pour l'avancement des sciences et des techniques de la documentation (ASTED), 2014
Ce document est protégé par la loi sur le droit d'auteur. L'utilisation des services d'Érudit (y compris la reproduction) est assujettie à sa politique d'utilisation que vous pouvez consulter en ligne.

https://apropos.erudit.org/fr/usagers/politique-dutilisation/ 


\section{Le gestionnaire de projet face aux défis des bibliothèques du XXI ${ }^{\mathrm{e}}$ siècle}

\author{
JEAN ROY \\ Gestionnaire de projet \\ roy.jean@videotron.ca
}

\begin{abstract}
RÉSUMÉ | ABSTRACT | RESUMEN
Le gestionnaire de projet doit s'adapter à de nombreuses contraintes, dont de nouvelles d'ordre technologique et environnemental. Quatre exemples servent à illustrer cette évolution de son rôle : la Grande Bibliothèque, les Bibliothèques du Boisé et SaulBellow de la Ville de Montréal, et la future bibliothèque du site Outremont de l'Université de Montréal.

\section{The Project Manager and the Challenges of Libraries in the $21^{\text {st }}$ Century}

The project manager must consider several constraints, namely technological and environmental. Four examples illustrate the evolution of this role: the Grande bibliothèque, the Boise and SaulBellow libraries of the City of Montréal and the future library of the Outremont site of the Université de Montréal.

\section{El gestor del proyecto ante los desafíos de las bibliotecas del siglo xxi}

El gestor del proyecto debe adaptarse a numerosos desafíos, especialmente los vinculados con las novedades tecnológicas $y$ medioambientales. Cuatro ejemplos permiten ilustrar la evolución de esta función: la Gran Biblioteca, las bibliotecas de Boisé y SaulBellow de la ciudad de Montreal, y la futura biblioteca del sitio Outremont de la Universidad de Montreal.
\end{abstract}

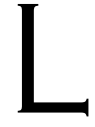

E GESTIONNAIRE DE PROJET DOIT FAIRE FACE À DE nouveaux défis lorsqu'il prend en charge la coordination et la supervision de la construction et de l'aménagement d'une bibliothèque. Outre son mandat de base qui consiste à livrer un bâtiment dans le respect des budgets et des délais, à la satisfaction du donneur d'ordres, de l'utilisateur - le bibliothécaire professionnel - et de l'usager, il doit prendre en compte les nouvelles réalités qui ont transformé l'univers des bibliothèques au cours des dernières années.

D'abord, une bibliothèque n'est pas un lieu ordinaire. Espace traditionnel et souvent chargé d'histoire, dédié à la lecture et à l'entreposage des documents, elle est devenue bien autre chose, au fil des siècles, sans renier pour autant sa vocation première. Aujourd'hui, à la fois maison de culture, de lecture, de mémoire, lieu de rencontre et de convivialité, lieu d'expositions, de détente et de pédagogie, elle s'affirme comme un endroit où le livre réel fait aussi place au document virtuel, où les mots voisinent les images, où l'écran plat et le numérique cohabitent avec les bonnes vieilles étagères. La bibliothèque offre l'accès au savoir à tous et participe en ce sens à la démocratisation de la culture et des connaissances, tout en favorisant l'innovation. De plus, on exige de la bibliothèque qu'elle soit non seulement fonctionnelle mais également belle et qu'elle respecte les règles fondamentales du développement durable.

Autrement dit, le gestionnaire du projet a dû s'adapter à ces nouvelles contraintes fonctionnelles, esthétiques et architecturales, sociales et financières, mais aussi technologiques et environnementales. Ces nouvelles règles imposent l'intervention de nouveaux joueurs à caractère " technique " dans le processus de réalisation du projet : architectes, ingénieurs de structure, concepteurs et spécialistes de nouvelles technologies.

L'exemple qui illustre le mieux cette évolution du rôle du gestionnaire de projet est celui du bâtiment de la Grande Bibliothèque, à Montréal, aujourd'hui partie intégrante de Bibliothèque et Archives nationales du Québec (BAnQ). J'ai eu l'honneur et le privilège de diriger ce prestigieux projet. La Grande Bibliothèque préfigure cette nouvelle génération d'établissements. Elle a démocratisé cette approche et ce concept de lieu de culture et de partage des idées du $\mathrm{XXI}^{\mathrm{e}}$ siècle 
qui s'impose pour tout nouveau projet de même nature. Pour Lise Bissonnette, alors présidente-directrice générale, ce lieu est à la fois bibliothèque nationale, archives nationales, Grande bibliothèque publique et bibliothèque virtuelle. Dans le Rapport annuel BAnQ 20052006, elle écrivait que "BAnQ, devenue au cours des derniers mois la plus importante institution culturelle du Québec par sa taille, la diversité de ses missions et sa présence dans les grands centres comme en régions, a rencontré ses publics $»^{1}$.

Il s'agissait donc tout à la fois de bâtir un monument phare de la culture et du savoir, non exclusivement livresque et s'intégrant parfaitement à son environnement urbain du centre-ville, au cœur du Quartier latin. Il fallait répondre aux attentes des professionnels, futurs locataires du lieu, et à celles de milliers de citoyens et de touristes qui le fréquenteraient quotidiennement. On devait combiner l'utile, l'agréable, le convivial, le modernisme et le traditionnel à la vocation première du bâtiment, tout en l'adaptant aux réalités technologiques de notre époque. Mais on ne devait pas oublier qu'une bibliothèque, si " Grande » soit-elle, reste... une bibliothèque.

L'un des plus grands défis fut de trouver l'équilibre entre le rendu du programme par l'architecte, les choix de design à la suite d'un concours international d'architecture et la conception du mobilier, qui avait également fait l'objet d'un concours national. Il faut savoir que la présence du mobilier (tables, chaises, lampes, rayonnages, etc.) s'avère déterminante dans le volume du lieu. Il doit être harmonisé avec l'architecture intérieure, tout en offrant toutes les fonctionnalités attendues. L'espace constitue un tout.

Il m'a donc fallu jouer le rôle de chef d'orchestre et de facilitateur, mais aussi d'arbitre. Canaliser le talent, parfois un peu "débordant ", de l'architecte et du designer, mais aussi comprendre l'artiste en eux. Il m'a fallu adopter la culture de l'ingénieur en structure, répondre aux inquiétudes de l'utilisateur final et anticiper la demande d'un usager de plus en plus exigeant et «branché ».

Être raisonnable, éviter la démesure, mais accepter un grain de folie. Et toujours respecter les limites budgétaires alors que de plus en plus, les concours architecturaux bonifient grandement les projets, améliorent leur conception, mais entraînent aussi parfois des contraintes financières supplémentaires.

L'avenir dira si le pari fut réussi totalement, mais j'ai la modestie de croire que oui, si l'on fait le bilan neuf ans après l'ouverture de ce nouveau temple de la culture et du savoir qu'est la Grande Bibliothèque. Déjà, la première année d'opération dépassait du double les prévisions de fréquentation.

Les nouvelles bibliothèques de Montréal telles que celle du Boisé, dans l'arrondissement Saint-Laurent, ou celle de Saul-Bellow, dans l'arrondissement de Lachine, sont dans la droite lignée de la tendance de construire des établissements " modernes, attrayants, fonctionnels et ouverts sur leur communauté " (extrait de la présentation du projet Saul-Bellow). On vise souvent la certification LEED, sceau d'excellente conduite environnementale.

Dernièrement, je me suis consacré à la future bibliothèque du site Outremont de l'Université de Montréal (UdM). Là encore, l'approche de la bibliothèque préconisée par l'UdM est fort novatrice si on la compare aux bibliothèques universitaires construites dans les années 1990. Cette nouvelle bibliothèque doit s'inscrire dans un projet structurant de requalification complète d'un vaste secteur de Montréal, autrefois friche industrielle et délaissée depuis une décennie.

Cette nouvelle bibliothèque universitaire sera dédiée aux sciences (chimie, biologie, physique, géographie) et le Programme fonctionnel et technique (PFT) en trace les lignes directrices : espace actif et proactif, priorité aux supports numériques, aux données ouvertes favorisant l'innovation et au partage de l'information. Le tout participera à la formation des futurs professionnels, chercheurs, experts et meneurs de demain qui façonneront des villes plus intelligentes, des entreprises plus performantes et une société plus juste et conviviale.

La culture, le savoir, le partage des connaissances et le croisement des expertises issues de nos bibliothèques auront, j'en suis convaincu, très largement inspiré ces acteurs du changement, toutes générations confondues, que sont les utilisateurs et les usagers de nos établissements du savoir. Et les gestionnaires de projets, modestement, y auront contribué avec fierté.

\footnotetext{
1. Bibliothèque et Archives nationales du Québec (BAnQ). Rapport annuel BAnQ 2005-2006. <http://www.banq.qc.ca/a_propos_banq/rapports_annuels/2005-2006> (consulté le 30 mars 2014).
} 